
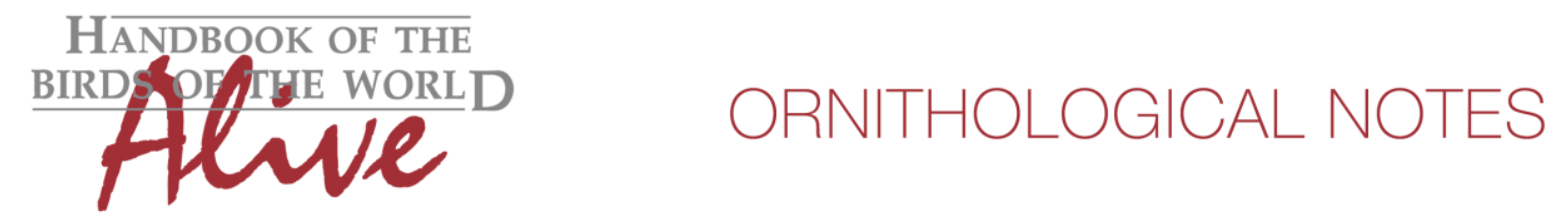

\title{
Notes on the vocalizations of Black-and-white Triller (Lalage melanoleuca)
}

Peter Boesman

In the following we briefly analyze and compare voice of the two races of Black-and-white Triller (Lalage melanoleuca). We also try to quantify the extent of any vocal differences using the criteria proposed by Tobias et al. (2010), as a support for taxonomic review.

We have made use of sound recordings available on-line from Xeno Canto (XC), Macaulay Library (ML) and Avian Vocalization Center (AVoCet), and a larger set kindly provided by Rob Hutchinson, for a total of 8 recordings of minor and 15 of melanoleuca.

Song of both taxa is a short phrase repeated several times (typically 3-12). After a pause either this same song boud is repeated, or there is a switch to a slightly different one. The phrase typically consists of one or more short buzzy/scratchy notes followed by one or more whistles.

In melanoleuca, there seem to be on average more buzzy/scratchy notes, with longer series as an introduction to an entire song boud, and the whistles are typically overslurred (sounding 'weew'). In minor, there are usually only one or two buzzy/scratchy notes, and whistles are typically NOT overslurred (sharply rising or falling, or underslurred).

Also, in melanoleuca, the song boud may have two alternating slightly different phrases, something not found clearly in the recordings of minor (some examples are given in Fig. 1).

Differences are thus quite subtle or with overlapping characteristics, but nonetheless some are clearly quantifiable:

The longest whistles in every phrase of melanoleuca are longer than in minor (range 0.17$0.45 \mathrm{~s}$ vs. $0.05-0.22 \mathrm{~s}$ ). The whistles in every phrase of melanoleuca reach marginally lower frequencies than in minor (range $1500-1700 \mathrm{~Hz}$ vs. $1650-1950 \mathrm{~Hz}$ ).

\section{Calculation of Effect Size:}

\begin{tabular}{llll}
\hline & \multicolumn{1}{c}{ minor } & melanoleuca & Effect Size \\
Note length & Av. 0.16s SD 0.049s & Av. 0.276s SD 0.06s & 2.11 \\
Min. Freq. & Av. $1764 \mathrm{~Hz}$ SD 109Hs & Av. $1573 \mathrm{~Hz} \mathrm{SD} \mathrm{134Hz}$ & 1.56
\end{tabular}

When applying Tobias criteria, this leads to a total calculated vocal score of $2+1=3$ 


\section{HANDBOOK OF THE BIRDSPF THE WORLD Aluve}

\section{ORNITHOLOGICAL NOTES}
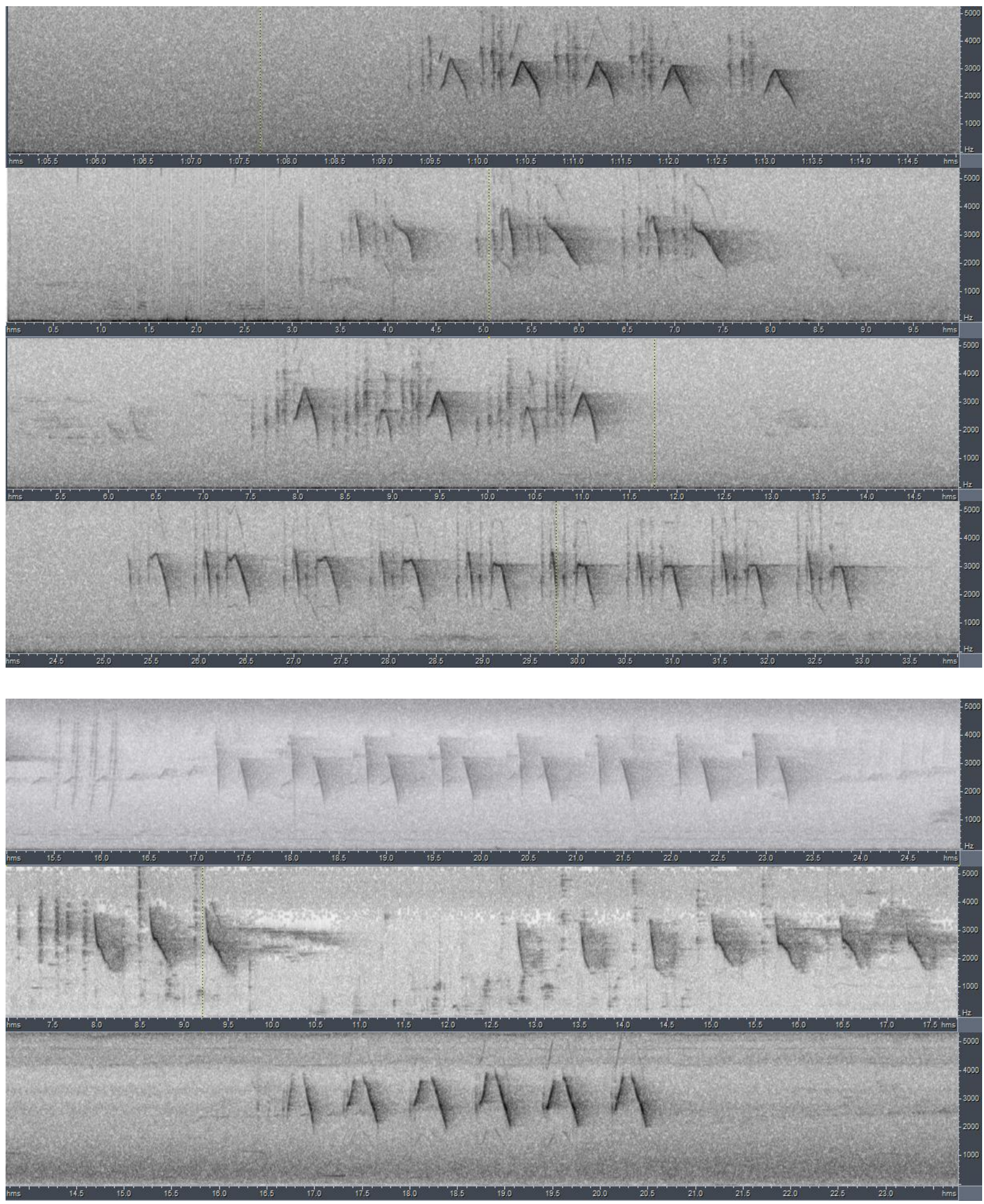

Figure 1: typical song of melanoleuca (top four) and minor (bottom three) 
This note was finalized on 7th January 2016, using sound recordings available on-line at that moment. We would like to thank in particular the sound recordists: Desmond Allen, Rob Hutchinson, Robert Kennedy, Mike Nelson and Pam Rasmussen.

\section{References}

Tobias, J.A., Seddon, N., Spottiswoode, C.N., Pilgrim, J.D., Fishpool, L.D.C. \& Collar, N.J. (2010). Quantitative criteria for species delimitation. Ibis 152(4): 724-746.

\section{Recommended citation}

Boesman, P. (2016). Notes on the vocalizations of Black-and-white Triller (Lalage melanoleuca). HBW Alive Ornithological Note 181. In: Handbook of the Birds of the World Alive. Lynx Edicions, Barcelona. (retrieved from http://www.hbw.com/node/932118 on 24 August 2016). 